\title{
Building Maintenance Management
}

\author{
Title: Building Maintenance Management Authors: Barrie Chanter and \\ Peter Swallow \\ Publisher: Blackwell Publishing Ltd., \\ Oxford, UK \\ Publication Date: (2007) 2nd edn
}

ISBN: 9781405135061

Details: Paperback, 336 pages

List Price: $£ 34.50$

Journal of Building Appraisal (2007) 3, 239-240. doi:10.1057/palgrave.jba.2950079

The maintenance manager for a large private school recently asked me for strategic advice to organise the programming and procurement of repairs to its large portfolio of school buildings. I wish I had read this book at the time!

Building Maintenance Management is a call to arms for facilities managers or anyone charged with maintaining buildings. It is equally relevant to those working in the public or private sectors, and provides a very helpful overview that benefits students and practitioners alike.

Building maintenance is often seen as the poor relation of the property and construction industries. This book seeks to counter that by clearly setting out options for asset management planning, acquisition of services, and operation of direct versus indirect labour. It also includes outsourcing administration and monitoring through benchmarks or KPIs.

Most building sectors are covered - housing, education, health, local authority and commercial - with insights into the factors peculiar to each. The book suggests that the quality of a person's surroundings greatly influences their well-being and productivity a principle with which I strongly agree.

The authors also consider lifecycle costing and financial appraisal techniques, to ensure best value for organisations. Different types of maintenance - routine, planned, cyclical, unplanned or reactive and component replacement - are clearly explained, along with general approaches to procurement and management.

The regulatory aspects of building maintenance are well covered. Legislative requirements for maintenance are succinctly set out, with a simple summary of the major Acts and Regulations particularly affecting the workplace and the health and safety of occupants.

Far too often, maintenance regimes, especially planned preventative maintenance, fail due to poor information management. The authors try to help the practitioner by steering him or her through the planning and implementation stages. They also describe different forms of data collection, as well as methods of holding, manipulating, using and controlling large amounts of information.

Management controls such as programming, budgeting, costing and their reporting are discussed, along with practical challenges to their implementation, such as contractor selection, procurement and the different forms of service agreements and contracts available, from traditional forms (JCT) to PFI, PPPs and others. 
The authors have succeeded in producing a well-structured and understandable take on an unloved sector that often involves a huge financial commitment for companies and organisations.

In an era when sustainability and the efficient use of the world's resources have become paramount considerations, this book highlights practical ways of putting these principles into practice. Through effective management of building maintenance, both human and material resources can be best used and the longevity of our building stock maximised.

David Mann

Partner

Tuffin Ferraby Taylor LLP

The Tower Building

11 York Road

London SE1 7NX, UK

Tel: +44 (0) 2079287998

Mob: +44 (0) 7973310623

Fax: +44 (0) 2079282779

E-mail:dmann@tftconsultants.com

Web: www.tftconsultants.com 